\title{
Wicking Behavior and Drying Capability of Functional Knitted Fabrics
}

\begin{abstract}
Liquid transporting and drying rate are two vital factors affecting the physiological comfort of sport garments. In this study, plated knitted fabrics produced with functional fiber yarns in the back of the knit (close to the body), combined with polypropylene or polyester in the face (outer surface) were tested in terms of their wicking behavior and drying rate capacity. Functional knitted fabrics were evaluated by vertical and horizontal wicking tests. The drying capability was assessed by drying rate tests under two different conditions, namely, at $20 \pm 2^{\circ} \mathrm{C}$ and $65 \pm 3 \%$ relative humidity and, in an oven, at $33 \pm 2^{\circ} \mathrm{C}$, in order to simulate the human body temperature. The influence of the functional fiber used and that of the ground material, polyester or polypropylene, was analyzed and discussed.
\end{abstract}

Key words materials, materials performance, materials wicking, chemistry

\section{Introduction}

Liquid transporting and drying rate of fabrics are two vital factors affecting the physiological comfort of garments [1$3]$. The moisture transfer and quick dry behaviors of textiles depend mainly on the capillary capability and moisture absorbency of their fibers. These characteristics are especially important in sport garments next to the skin or in hot climates. In these situations, textiles are able to absorb large amounts of perspiration, draw moisture to the outer surface and keep the body dry. Therefore, in order to optimize these functionalities in sport clothing, it is necessary to investigate the wicking behavior and quick drying capability of functional knitted fabrics.

Liquid transfer mechanisms include water diffusion and capillary wicking, which are determined mainly by effective capillary pore distribution, pathways and surface tension, whereas the drying rate of a material is related to the macromolecular structure of the fiber.

\author{
R. Fangueiro', A. Filgueiras and F. Soutinho \\ Department of Textile Engineering. University of Minho. \\ Guimarães, Portugal
}

Xie Meidi

Department of Knitting and Garment. Textile Institute of Dong Hua University, China
Wicking is the spontaneous flow of a liquid in a porous substance, driven by capillary forces. Washburn [4] proposed the well-known Lucas-Washburn kinetics equation to describe the relationship between wicking length and wicking time. Rita, Erik, Weiyuan, and Ramachandran et al. [5-8] investigated the wetting and wicking behavior of textiles. As capillary forces are caused by wetting, wicking is a result of spontaneous wetting in a capillary system. Wicking takes place only in wet fabrics or when fabrics come into contact with water, and the contact angle determines their wicking behavior. A lower contact angle results in higher wicking rates. Hartzell [9], Hsieh [10], Navaneetha and Selvarajan [11], and Van Der Meeren et al. [12] investigated methods to improve cotton fabric wettability. However, in materials based on natural fibers, wetting causes the fabric to swell, changing the capillary space position

\footnotetext{
${ }^{1}$ Corresponding author: e-mail: rfang@det.uminho.pt
} 
and affecting the wicking ability [3]. For most synthetic fabrics, wicking, however, will not take place due to their high contact angles. A number of hydrophilic finishing treatments can improve the capillary wicking of synthetic fibers, such as polyester and acrylic [13-15]. Different researchers have focused their attention on the geometric distribution of capillary inter-space in synthetic fiber assemblies, which affects the results of liquid quantity and the wicking time of capillary action [16]. Zhang et al. [16] simulated liquid flow in a fiber assembly by the combination of a kinetic analysis model of vertical capillary and a mathematical simulation model for a fiber bundle. In doing so, they analyzed and calculated various parameters of fiber bundles like fiber number, wicking height, instant wicking velocity as well as wicking time. The fiber bundles cross-section is considered as an advantage for liquid transporting. These investigations contribute towards developing the most optimized profile fiber.

Structure modification was researched in terms of its effect on liquid transporting in functionally knitted fabrics. Research was carried out using different fiber combinations of polypropylene or polyester fibers and other hydrophilic fibers with various knitted structures [7,17].

In this paper we study the wicking behavior and the drying rate of plated knitted fabrics produced with polypropylene or polyester fibers on the knit face while functional, synthetic or artificial fibers are used as the back of the knitted structure. Two main evaluation methods of liquid transfer behavior through textile materials were used, that is, vertical wicking and horizontal wicking. Drying capability testing was carried out under two different conditions: $20 \pm 2^{\circ} \mathrm{C}$ and $65 \%$ relative humidity and at the human body temperature $\left(33^{\circ} \mathrm{C}\right)$. These two parameters play an important role in the performance of clothing for professional sport players.

\section{Materials}

Table 1 shows the specifications of the yarns used to produce the knitted fabrics for testing. The yarns used cover a wide range of functional fibers, including polyester trilobal flat (PES), polypropylene (PP), polyamide (PA), elastane (EL), polyester Coolmax ${ }^{\circledR}$ (CL), PBT, Dry-release ${ }^{\circledR}$ (DR) and viscose Outlast ${ }^{\circledR}$ (VO).

Dry-release ${ }^{\circledR}$ is a commercial brand of a moisture management and quick drying yarn presenting a combination of polyester/cotton $(85: 15 \%)$. Outlast ${ }^{\circledR}$ is a commercial brand of a $100 \%$ viscose thermoregulation fiber. Coolmax ${ }^{\circledR}$ is commercial brand of a $100 \%$ polyester fiber with moisture management and quick drying properties. PBT is a polybutylene terephthalate fiber with high elasticity.

Two sets of plated knitted fabrics were designed and produced. Set 1 presents polyester trilobal flat on the knit face, and PA with EL, polyester Coolmax ${ }^{\circledR}$, PBT, Dryrelease ${ }^{\circledR}$ and viscose Outlast ${ }^{\circledR}$, designated as PES-EL, PESCM, PES-PBT, PES-DR, PES-VO, respectively, on the knit back. Set 2 presents polypropylene on the knit face and the same yarns on the knit back. The knitted structure used is shown in Figure 1. The face yarn is polyester trilobal flat or

Table 1 Specifications of the yarns used.

\begin{tabular}{|c|c|c|c|}
\hline \multicolumn{2}{|c|}{ Yarn type } & \multirow{2}{*}{$\begin{array}{c}\text { Yarn linear density (Tex) } \\
11\end{array}$} & \multirow{2}{*}{$\frac{\text { Filament linear density (dTex) }}{1.58}$} \\
\hline Knit face yarn & PES trilobal flat & & \\
\hline & Polypropylene (PP) & 8.7 & 2.17 \\
\hline Recovered yarn & Polyamide (PA) & 2.4 & 3.49 \\
\hline \multirow{2}{*}{$\begin{array}{l}\text { Knit back yarn (functional } \\
\text { fiber) }\end{array}$} & Elastane (EL) & 2.2 & - \\
\hline & PES Coolmax ${ }^{\circledR}(\mathrm{CL})$ & 8.7 & 1.84 \\
\hline
\end{tabular}

Figure 1 Knitted structure used.
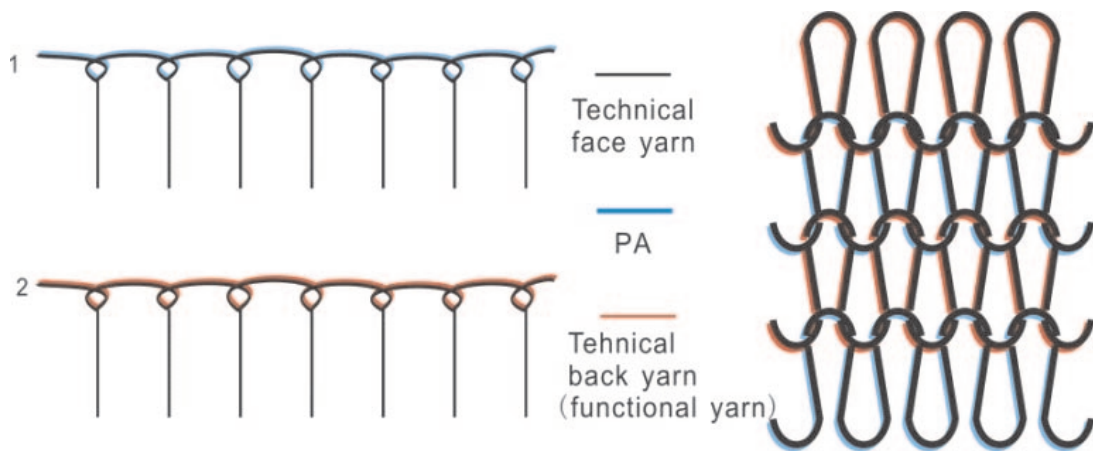
Table 2 Dimensional properties of the knitted fabrics.

\begin{tabular}{|c|c|c|c|c|c|c|c|c|c|}
\hline \multirow[t]{2}{*}{ Fabric } & & \multicolumn{3}{|c|}{ Loop length (cm/100 loops) } & \multirow{2}{*}{$\begin{array}{l}\text { Cover } \\
\text { factor }\end{array}$} & \multirow{2}{*}{$\begin{array}{l}\text { Areal mass } \\
\qquad\left(\mathrm{g} / \mathrm{m}^{2}\right)\end{array}$} & \multicolumn{2}{|c|}{ Density } & \multirow{2}{*}{$\begin{array}{c}\text { Thickness } \\
(\mathrm{mm})\end{array}$} \\
\hline & & Knit face yarn & PA & Functional yarn & & & Wales/cm & Courses/cm & \\
\hline \multirow[t]{5}{*}{ Set 1} & PES-EL & 15.14 & 15.81 & 15.78 & 21.91 & 129.47 & 16.0 & 19.6 & 0.99 \\
\hline & PES-CL & 15.73 & 15.56 & 15.75 & 21.08 & 130.90 & 14.2 & 18.4 & 1.15 \\
\hline & PES-PBT & 14.09 & 15.13 & 14.70 & 23.54 & 118.54 & 15.3 & 19.6 & 1 \\
\hline & PES-DR & 14.33 & 15.07 & 16.48 & 23.14 & 139.79 & 13.9 & 18.0 & 1.29 \\
\hline & PES-VO & 15.10 & 16.20 & 17.77 & 21.96 & 138.28 & 14.8 & 17.4 & 1.28 \\
\hline \multirow[t]{5}{*}{ Set 2} & PP-EL & 15.24 & 15.31 & 15.23 & 19.35 & 126.25 & 14.8 & 23.3 & 1.21 \\
\hline & $\mathrm{PP}-\mathrm{CL}$ & 15.19 & 15.30 & 15.97 & 19.42 & 121.62 & 14.1 & 19.2 & 1.21 \\
\hline & PP-PBT & 14.86 & 15.24 & 15.23 & 19.85 & 113.99 & 15.0 & 22.4 & 1.22 \\
\hline & PP-DR & 15.18 & 15.17 & 16.28 & 19.43 & 131.49 & 14.0 & 18.0 & 1.39 \\
\hline & PP-VO & 14.68 & 15.25 & 16.78 & 20.09 & 132.48 & 13.9 & 18.1 & 1.38 \\
\hline
\end{tabular}

polypropylene, respectively, and the ground yarns are, alternately, PA combined with the fibers already mentioned.

Table 2 presents the dimensional properties of the knitted fabrics produced on a circular weft-knitting machine, E28.

\section{Test Methods}

\section{Vertical Wicking Testing}

Vertical wicking tests were performed on the apparatus shown in Figure 2. Five specimens of $200 \mathrm{~mm} \times 25 \mathrm{~mm}$ cut along the walewise and coursewise directions were prepared. The specimen was suspended vertically with its bottom end dipped in a reservoir of distilled water. In order to ensure that the bottom ends of the specimens could be immersed vertically at a depth of $30 \mathrm{~mm}$ into the water, the bottom end of each specimen was clamped with a $1.2 \mathrm{~g}$ clip, as shown in Figure 2. The wicking heights, measured every minute for $10 \mathrm{~min}$, were recorded for a direct evaluation of the fabric's wicking ability.

\section{Horizontal Wicking Testing}

Figure 3 shows the apparatus used to evaluate the horizontal wicking rate, under $20 \pm 2^{\circ} \mathrm{C}$ and $65 \pm 2 \%$ relative humidity. In the horizontal wicking apparatus, the specimen (size $200 \mathrm{~mm} \times 200 \mathrm{~mm}$ ) is placed horizontally, a tiny drop of water is placed on the fabric and the water absorption takes place by wicking and wetting through the pores. The water is supplied continuously from a reservoir by siphoning. The reservoir is kept on an electronic balance, which enables the recording of the water mass absorbed by the

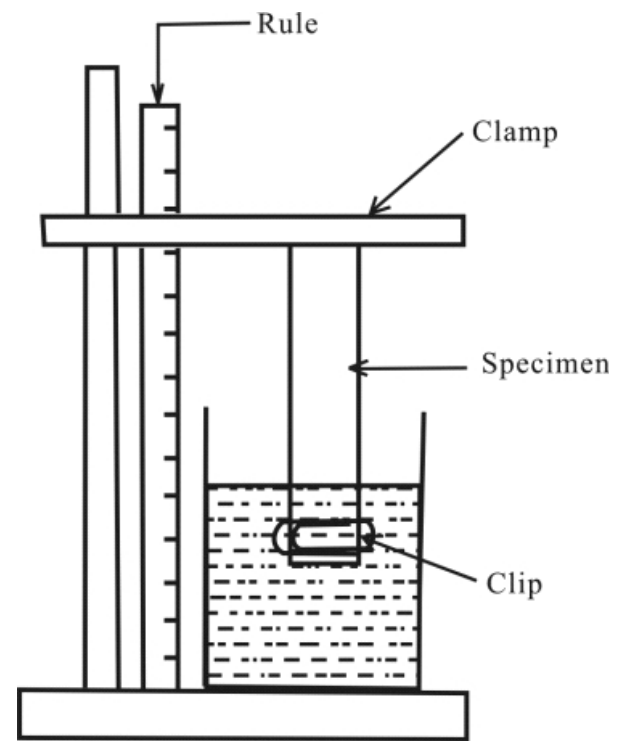

Figure 2 Vertical wicking apparatus.

fabric. Because the mass absorbed by the sample is related to the sample thickness, water absorption per unit of thickness is used to evaluate the horizontal wicking ability.

\section{Drying Rate Testing}

Drying capability is evaluated by the drying rate of the fabric. The specimen is cut as a $200 \mathrm{~mm} \times 200 \mathrm{~mm}$ square, put on the plate of the balance, and the drying weight is recorded as $w_{f}(\mathrm{~g})$. The water weight added to the fabric, equal to $30 \%$ of the dry sample weight before testing, des- 
Figure 3 Horizontal wicking apparatus.

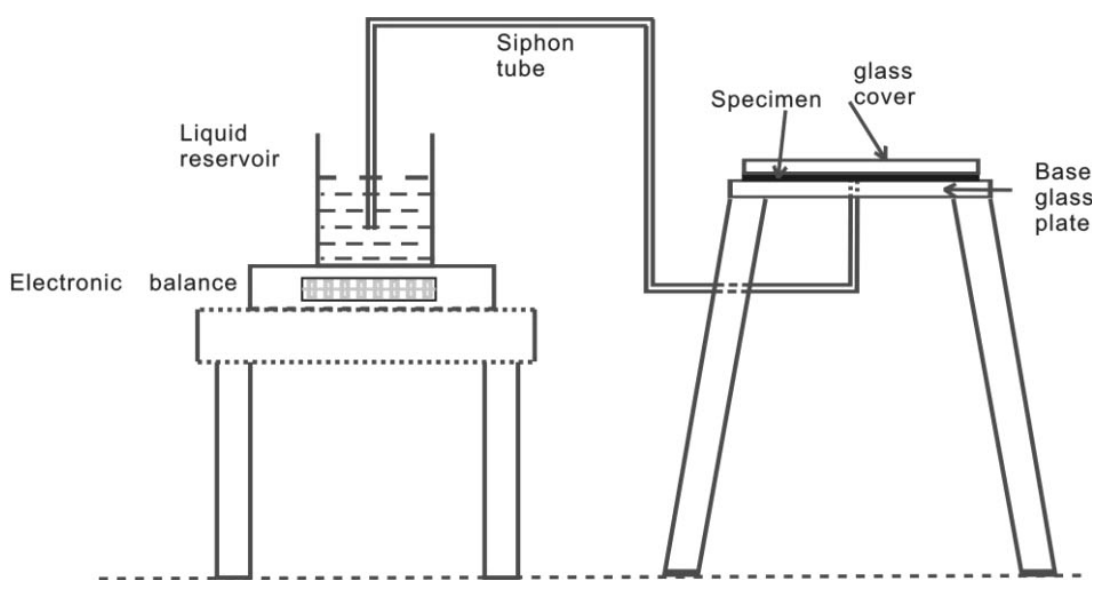

ignated $w_{o}(\mathrm{~g})$. Record the change of water, $w_{i}(\mathrm{~g})$ at regular intervals continuously for some time observation. Calculate the "Water Evaporating Rate" (WER) by equation (1) to express the change of water weight remained in the specimen over time, to draw the evaporating curve from $100 \%$ to $0 \%$.

$$
\operatorname{WER}(\%)=\frac{\left(w_{0}-w_{i}\right)}{\left(w_{0}-w_{f}\right)} \times 100 \%
$$

In order to assess the quick dry capability of the fabric in different conditions, two testing conditions were chosen, that is, $20 \pm 2^{\circ} \mathrm{C}$ and $65 \pm 5 \%$ relative humidity, and temperature of $33 \pm 2^{\circ} \mathrm{C}$. For the first condition, the mass of water, $w_{i}(\mathrm{~g})$, was measured every $5 \mathrm{~min}$ continually for $60 \mathrm{~min}$. For the second condition, the mass of water $w_{i}(\mathrm{~g})$ was recorded continually, every $2 \mathrm{~min}$, for $12 \mathrm{~min}$.

\section{Results And Discussion}

\section{Wicking Ability}

\section{Effect of Different Ground Yarns on the Vertical and Horizontal Wicking Performance}

Figures 4 and 5 show, respectively, the vertical wicking results obtained for fabric Sets 1 and 2. Horizontal wicking curves of Sets 1 and 2 are shown in Figures 6 and 7.

From Figures 4 and 5, it can be seen that, in the first five minutes, the wicking height of the fabric PES-VO is higher than that of the others, and the wicking height of the fabric EL is lower. Figures 4(a) and 5(a) show that, in the first minute, the wicking height of the fabrics with Coolmax ${ }^{\circledR}$ (CL) in the walewise direction, is similar to that of those with PBT, and the wicking height of fabrics with Dry-release ${ }^{\circledR}$ (DR) is similar to those of fabrics with EL, whereas,

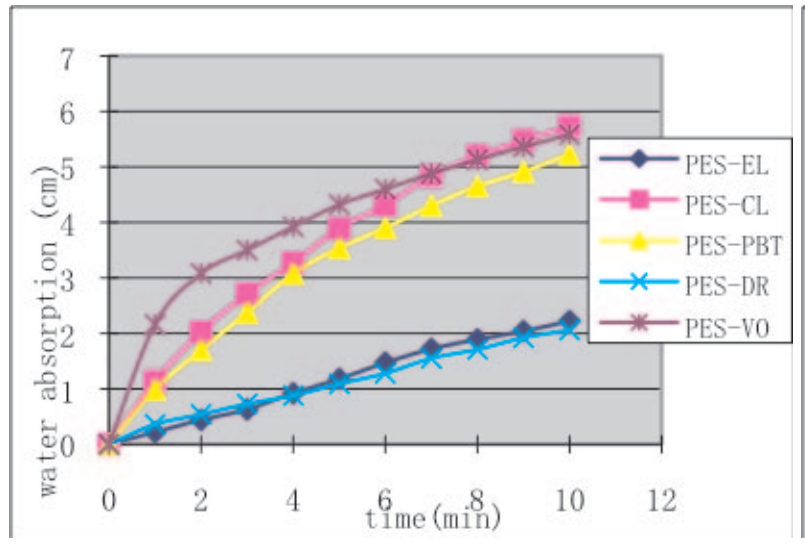

(a)

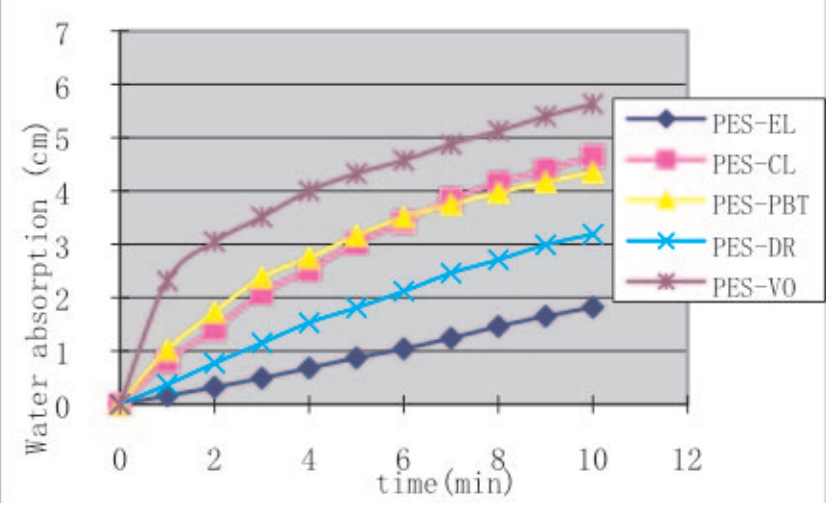

(b)

Figure 4 Vertical wicking curves for Set 1 fabrics: (a) wale-wise direction, (b) course-wise direction. 


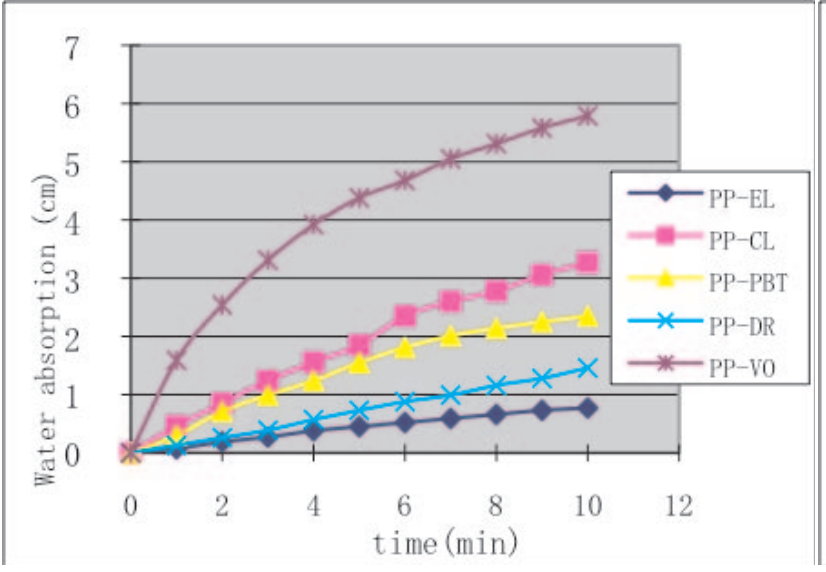

(a)

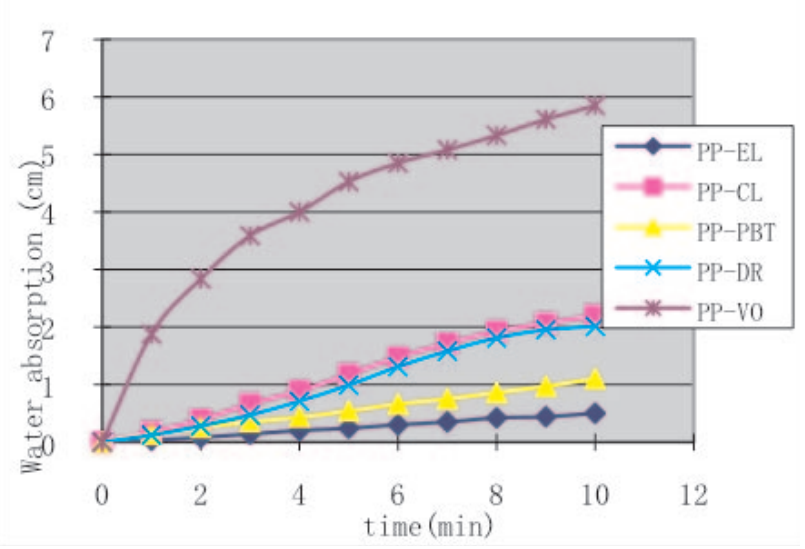

(b)

Figure 5 Vertical wicking curves for Set 2 fabrics: (a) wale-wise direction, (b) course-wise direction.

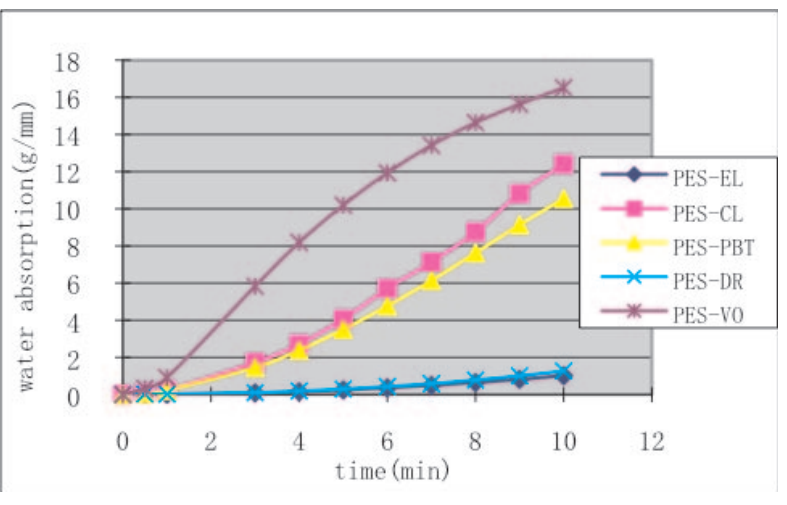

Figure 6 Horizontal wicking curves of Set 1 fabrics.

Figure 5(b) indicates that PP-Cl, PP-PBT, PP-DR and PPEL fabrics present similar wicking height in the coursewise direction for the first minute.

Moreover, Figures 6 and 7 indicate that PES-VO and PP-VO fabrics present the highest water absorption. The horizontal wicking ability of the fabrics with different functional yarns in the knit back are found to be: viscose Outlast $^{\circledR}$, Coolmax $^{\circledR}$, PBT, Dry-release ${ }^{\circledR}$, and EL.

The phenomenon can be attributed to the fabric's contact angle and the fiber's cross-sectional shape. These fabrics have been finished by the same chemical hydrophilic product. Viscose Outlast ${ }^{\circledR}$ and Coolmax ${ }^{\circledR}$ present irregular cross-sectional shapes. These two yarns can form more capillaries than the others. Moreover, viscose Outlast ${ }^{\circledR}$ is a hydrophilic fiber which has a good water absorption property. As soon as the fabric comes into contact with water, wicking and water absorbency cannot be separated and are

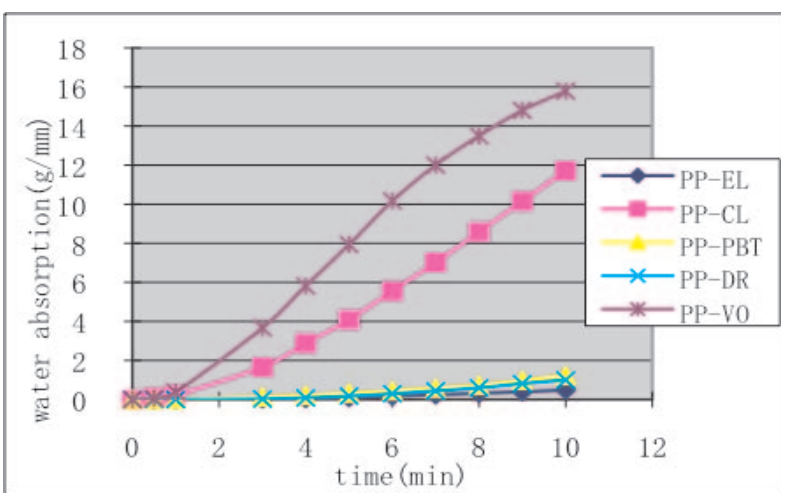

Figure 7 Horizontal wicking curves of Set 2 fabrics.

simultaneous, especially when the fabric is contacting water horizontally. Therefore, the fabric with viscose Outlast $^{\circledR}$ yarn is observed to have the best behavior for wicking, in both the vertical or horizontal directions, followed by Coolmax ${ }^{\circledR}$. Figure 8 presents the cross-section of the fibers used in this study. The cross-section of Dry-release ${ }^{\circledR}$ and PBT is round, but Dry-release ${ }^{\circledR}$ is a blended yarn of cotton and synthetic fibers so the wicking ability of the fabric with the Dry-release ${ }^{\circledR}$ ground yarn is worse than PBT.

\section{Effect of Different Knit Face Yarns on Wicking Ability}

Comparisons of vertical wicking height and horizontal wicking rate with the same knit back yarn and different knit face yarns at one minute and five minutes are shown in Figures 9 and 10. Figure 9 shows that virtual wicking height 


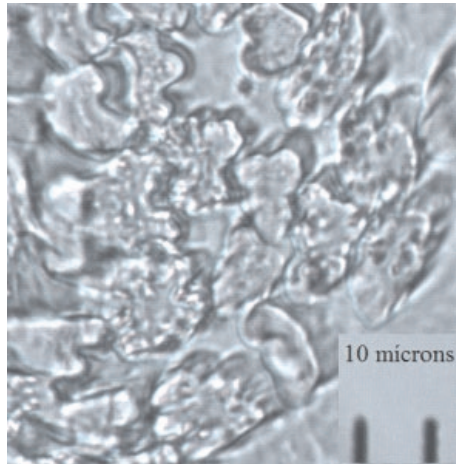

(a)

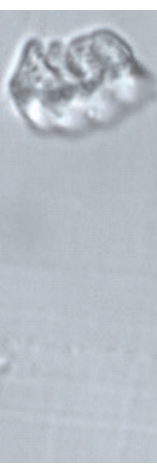

(b)

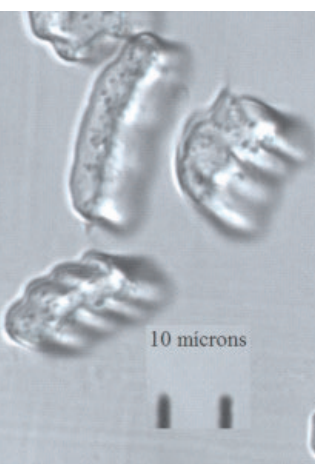

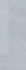

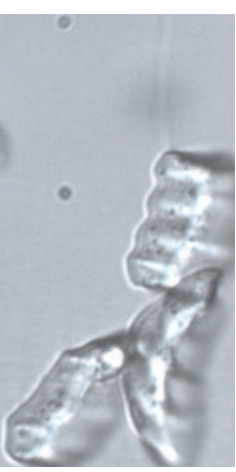

(c)

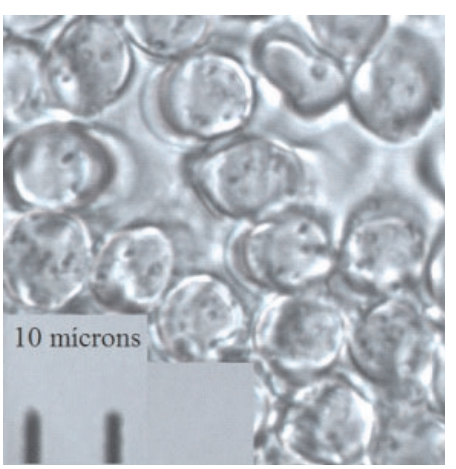

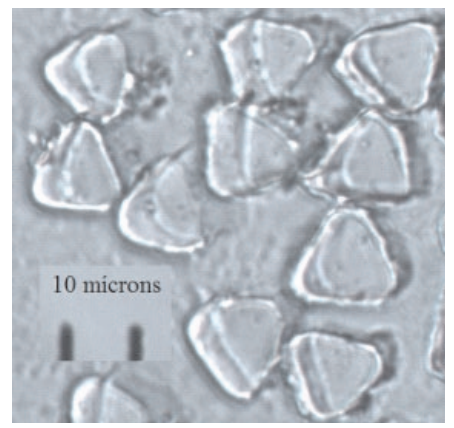

(d)

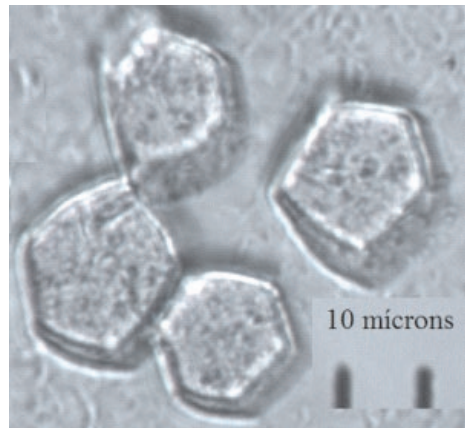

(e)

Figure 8 Fiber cross-sections: (a) viscose Outlast ${ }^{\circledR}$, (b) Coolmax ${ }^{\circledR}$. (c) Dry-release ${ }^{\circledR}$, (d) PES trilobal flat, (e) polypropylene.

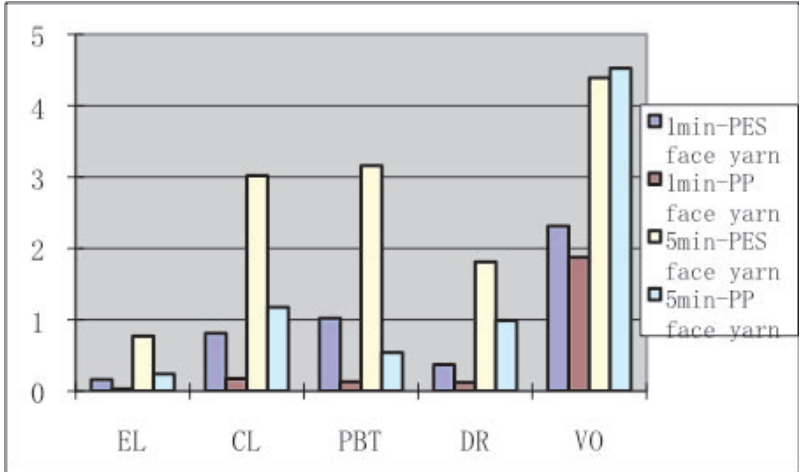

(a)

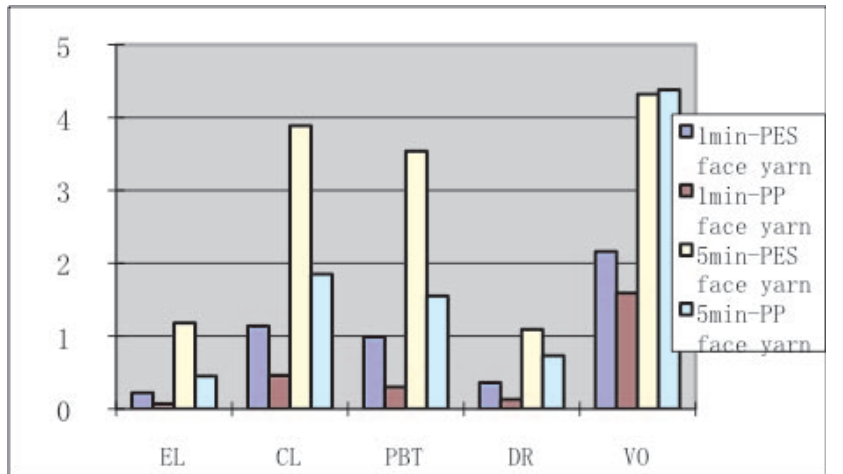

(b)

Figure 9 Vertical wicking ability of the fabrics with the same knit back yarn and different knit face yarns at 1 and 5 min: (a) wale-wise direction, (b) course-wise direction.

of the fabric with PES trilobal flat yarn is better than that of the fabric with PP yarn. However, the PES-VO and PPVO fabrics display very similar behavior. Figure 10 shows water absorption per thickness of the fabric. The PES trilo- bal flat yarn is better that of the fabric with PP yarn. This is attributed to the cross-sectional shape and their fiber linear mass. Figure 11 indicates the triangular cross-section shape of the PES trilobal flat fiber, and the nearly round 


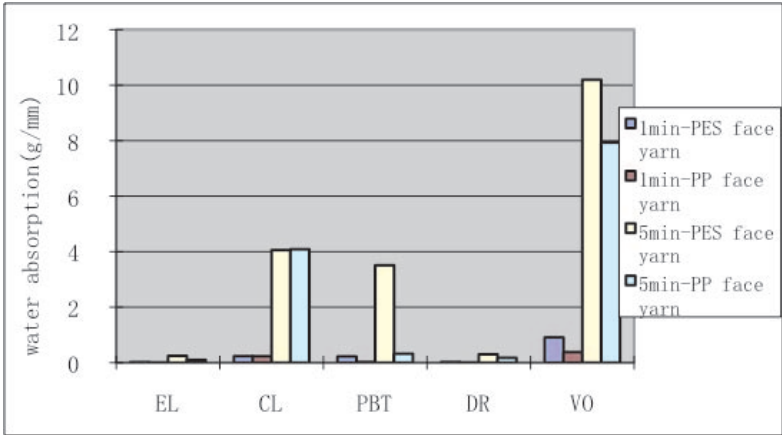

Figure 10 Horizontal wicking ability of the fabrics with the same knit back yarn and different face yarns at 1 and $5 \mathrm{~min}$.

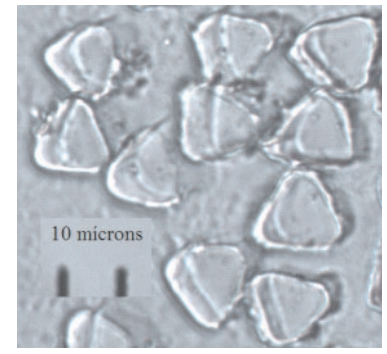

(a) PES trilobal flat

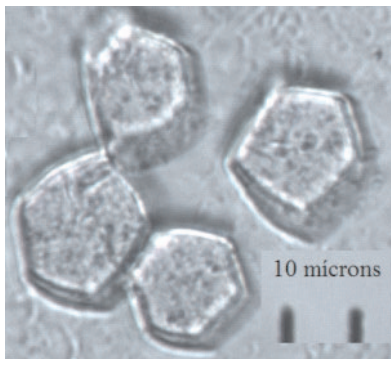

(b) PP
Figure 11 Cross section of the two technical face yarns used

cross-section shape of the PP fiber. Moreover, Table 1 shows that the linear mass per filament of the PES trilobal flat fiber is finer than that of the PP fiber. Therefore fabrics containing PES trilobal flat yarn combined with different functional fibers on the knit back transfer the moisture easily.

\section{Drying Rate}

\section{Effect of Different Ground Yarns on Quick Drying Capability}

Figures 12 and 13 show the WER vs. time curves of Sets 1 and 2 fabrics, at $20 \pm 2^{\circ} \mathrm{C}, 65 \pm 2 \%$ relative humidity. The WER vs. time curves of Sets 1 and 2 at $33 \pm 2^{\circ} \mathrm{C}$ in an oven are shown in Figures 14 and 15.

It can be seen from Figures 12 to 15 that the sequence of the WER of the fabrics with the same yarn and different functional plated yarns is PES-VO $<$ PES-EL $<$ PES-DR

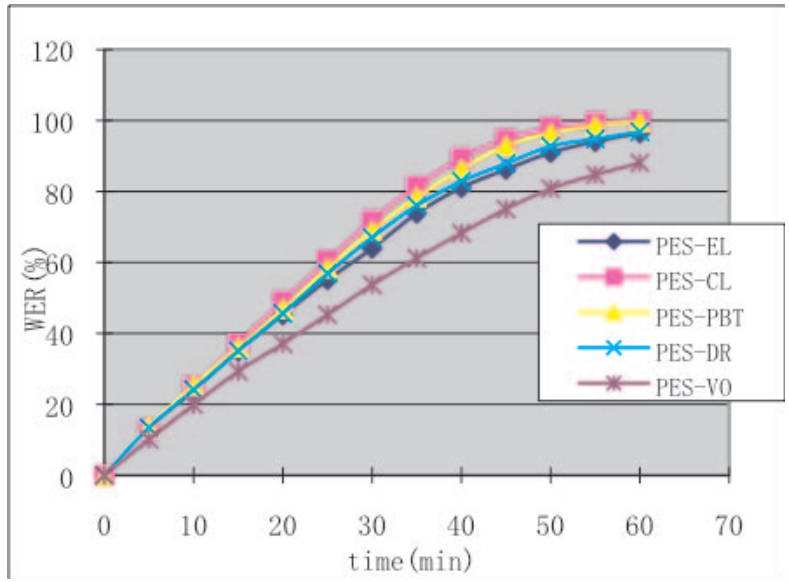

Figure 12 WER curves for Set 1 fabrics at $20 \pm 2$ C, $65 \pm 2 \%$ relative humidity.

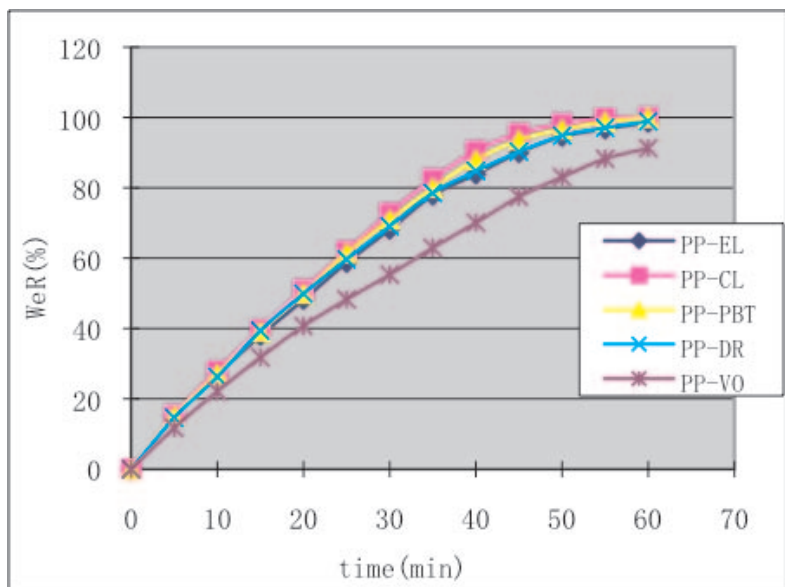

Figure 13 WER curves for Set 2 fabrics at $20 \pm 2$ C, $65 \pm 2 \%$ relative humidity.

$<$ PES-PBT $<$ PES-CL and PP-VO $<$ PP-EL $<$ PP-DR $<$ PP-PBT < PP-CL; a smaller difference is seen among samples tested in the oven at $33^{\circ} \mathrm{C}$. Wicking ability and moisture regain play an important role in the drying capability of the fabric. In the case of the low moisture regain of the fabric, the fabric with better wicking ability possesses the higher WER. Due to the number of hydroxyl groups available for bonding with water in viscose, its moisture regain is much higher than any other knit back yarn. The fabrics knitted with viscose Outlast ${ }^{\circledR}$ yarn in the knit back show poor quick drying capability regardless of the face yarn (PES trilobal flat or PP). The fabric with the Coolmax ${ }^{\circledR}$ 


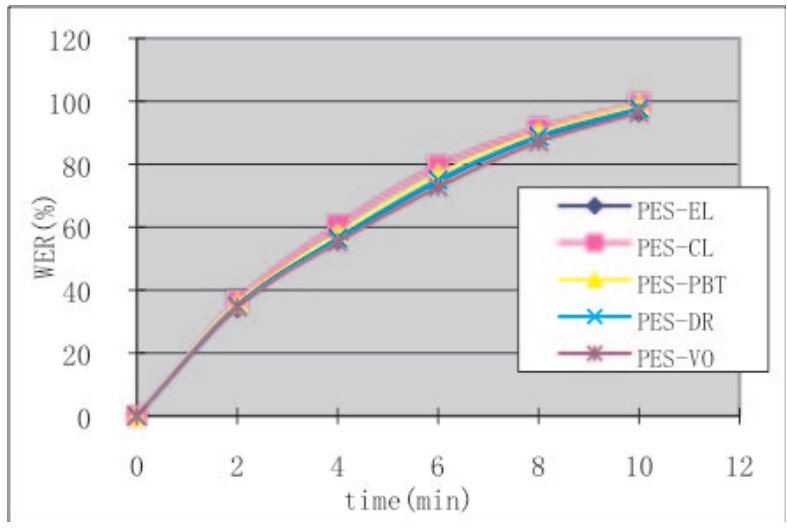

Figure 14 WER curves for Set 1 fabrics at $33 \pm 2^{\circ} \mathrm{C}$.

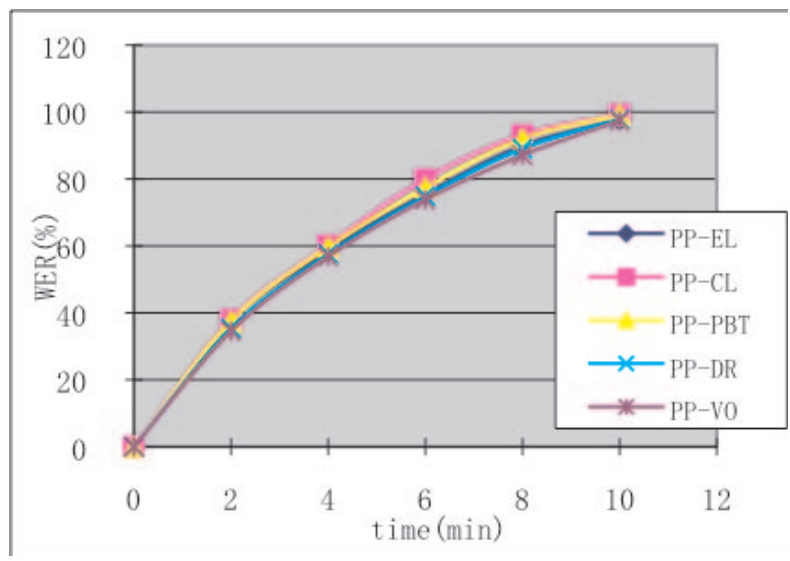

Figure 15 WER curves of Set 2 fabrics at $33 \pm 2^{\circ} \mathrm{C}$.

plated yarn shows better drying properties regardless of the face yarn (PES trilobal flat or PP).

\section{Effect of Different Face Yarns on Quick Dry Capability}

The comparisons of WER for two series of fabrics after 60 min, at $20 \pm 2^{\circ} \mathrm{C}$ and $65 \pm 2 \%$ relative humidity and after 10 min at $33 \pm 2^{\circ} \mathrm{C}$ in the oven are listed in Tables 3 and 4 , respectively.

Tables 3 and 4 indicate that the WER of the fabrics with the PES trilobal flat face yarn is lower than that of the fabrics with the PP face yarn for both testing conditions. This fact can be attributed to two aspects:

- PP fiber is a long-chain synthetic polymer composed of at least $85 \%$ by weight propylene and at standard
Table 3 WER after $60 \mathrm{~min}$, at $20 \pm 2{ }^{\circ} \mathrm{C}$ and $65 \pm 2 \%$ relative humidity.

\begin{tabular}{ccccc} 
PES-EL & PES-CL & PES-PBT & PES-DR & PES-VO \\
\hline $96.43 \%$ & $99.91 \%$ & $99.52 \%$ & $96.8 \%$ & $88.03 \%$ \\
\hline PP-EL & PP-CL & PP-PBT & PP-DR & PP-VO \\
\hline $98.59 \%$ & $100 \%$ & $100 \%$ & $98.88 \%$ & $91.27 \%$ \\
\hline
\end{tabular}

Table 4 WER after 10 min at $33 \pm 2^{\circ} \mathrm{C}$ in oven.

\begin{tabular}{ccccc} 
PES-EL & PES-CL & PES-PBT & PES-DR & PES-VO \\
\hline $96.63 \%$ & $99.14 \%$ & $98.82 \%$ & $97.69 \%$ & $96.42 \%$ \\
\hline PP-EL & PP-CL & PP-PBT & PP-DR & PP-VO \\
\hline $97.78 \%$ & $99.24 \%$ & $99.10 \%$ & $97.83 \%$ & $97.43 \%$ \\
\hline
\end{tabular}

condition the moisture regain of PP is very close to 0 . Even at saturation, regain ranges from 0 to $1 \%$.

- The PP fabrics have lower fabric weights than those using PES. When testing WER the weight of the PP is lower that of PES fabrics; therefore fabrics with a PP face demonstrate a higher drying rate than PES fabrics.

\section{Conclusions}

The wicking behavior and drying capability of different plated knitted functional fabrics, produced with functional fibers and polypropylene or polyester, were analyzed. The wicking behavior of fabrics is mainly determined by the effective capillary pore distribution and pathways as well as surface tension. The drying capability is related to the macromolecular structure of the fiber. Viscose Outlast ${ }^{\circledR} \mathrm{dem}$ onstrates the best wicking ability in both horizontal and vertical wicking, but its drying capability is low. Coolmax ${ }^{\circledR}$ shows a good wicking ability and the best drying capability. PBT shows better wickability and drying capability than EL. The comparison between the PP and PES combined with other functional fibers has shown that the functional knitted fabrics made with PP face yarn are worse in wicking ability and better in drying capability than that of fabrics using a face PES yarn.

\section{Abbreviations}

$\mathrm{CL}=$ polyester Coolmax ${ }^{\circledR} ; \mathrm{DR}=$ Dry-release $^{\circledR} ; \mathrm{EL}=$ elastane; $\mathrm{PA}=$ polyamide; $\mathrm{PES}=$ polyester trilobal flat; $\mathrm{PP}=$ polypropylene $; \mathrm{VO}=$ viscose Outlast $^{\circledR}$. 


\section{Acknowledgements}

This study has been developed in the framework of the ASIA-LINK Project $n^{\circ} 002$ (82158). The authors are grateful to the company SONICARLA for providing the samples for the present study.

\section{References}

1. Laughlin, R. and Davies, J., Some Aspects of Capillary Absorption in Fibrous Textile Wicking, Text. Res. J., 31, 904910 (1961).

2. Hollies, N., Kassinger, S., Barbara, W. and Herman, B., Water Transport Mechanisms in Textile Material, Part II: Capillarytype Penetration in Yarns and Fabrics, Text. Res. J., 27, 8-1327 (1957).

3. Yan, Z., Huaping, W., Chuanxiong, Z. and Yuehua, C., Modeling of Capillary Flow in Shaped Polymer Fiber Bundles. $J$. Mater. Sci., 42, 8035-8039 (2007).

4. Washburn, E., The Dynamics of Capillary Flow - Physics Review, 273-283 (1921).

5. Rita, M. and Randall, J., The Interaction of Water with Fabric, Text. Res. J., 68, 280-288 (1998).

6. Erik. K., Wetting and Wicking, Text. Res. J., 66, 660-668 (1996).

7. Weiyuan, Z., Jun, C., Wenfei, C. and Shi, L., Wetness Comfort of Fine Polypropylene, Fibre Fabrics. J. Text. Inst., 90, p. 252, (1997).
8. Ramachandran, T. and Kesavaraja, N., A Study on Influencing Factors for Wetting and Wicking Behavior, IE (I) J., TX, 84, 37-41 (2004).

9. Harzell, M. and Hsieh, Y., Enzymatic Scouring to Improve Cotton Fabric Wettability, Text. Res. J., 68, 233-241 (1998).

10. Hsieh, Y., Thompson, J., and Miller, A., Water Wetting and Retention of Cotton Assemblies as Affected by Alkaline and Bleaching Treatments, Text. Res. J., 62, 456-464 (1996).

11. Navaneetha K. and Selvarajan, V., Non-thermal Plasma Treatment for Hydrophilicity Improvement of Grey Cotton Fabrics, J. Mater. Process. Technol., 199, 130-139 (2008).

12. Van Der Meeren, P., Cocquyt, J., Flores, S., Demeyere, H., and Declercq, M., Quantifying Wetting and Wicking Phenomena in Cotton Terry as Affected by Fabric Conditioner Treatment, Text. Res. J., 72, 423-428 (2002).

13. You Lo, H. and Cram, L., Enzymatic Hydrolysis to Improve Wetting and Absorbency of Polyester Fabrics, Text. Res. J. 68, 311-319 (1998).

14. Ferrero, F., Wettability Measurements on Plasma Treated Synthetic Fabrics by Capillary Rise Method, Polym. Test., 22, 571-578 (2003).

15. Adler, M. M. and Walsh, W. K., Mechanisms of Transient Moisture Transport between Fabric, Text. Res. J., 54, 334-343 (1984).

16. Zhang, Y., Wang H., and Chen, Y., Capillary Effect of Hydrophobic Polyester Fiber Bundles with Noncircular Cross Section, J. Appl. Polym. Sci., 102, 1405-1412 (2006).

17. Hsieh, Y., Liquid Transport in Fabric Structures, Text. Res. J., 65, p. 299 (1995). 